\title{
Upregulation of the Vitamin D Receptor in the Nasal Mucosa of Patients With Allergic Rhinitis
}

\author{
Hyeon Geun Kim, MD, Da Bin Lee, MD, Tae Hoon Lee, MD, Bo Yoon Choi, MD, \\ Mun Soo Han, MD, Sang Hag Lee, MD, PhD, and Tae Hoon Kim, MD, PhD \\ Department of Otorhinolaryngology-Head \& Neck Surgery, Korea University College of Medicine, Seoul, Republic of Korea
}

Background and Objectives: Vitamin D modulates immunity, including that of allergic diseases, and plays its roles through contact with vitamin D receptors (VDR). Recent studies have shown that patients with allergic rhinitis have low systemic serum vitamin D level. However, the expression of VDR in local tissue such as human nasal mucosa has not been investigated. Our study demonstrated that, in nasal mucosa of normal controls and patients with allergic rhinitis.

Materials and Methods: Nasal mucosa were harvested from twenty-five patients who had normal nasal mucosa and twenty-five patients with allergic rhinitis. After the total RNA isolation, we performed reverse transcriptase-polymerase chain reaction, immunohistochemical staining and western blot analysis.

Results: VDR were expressed in submucosal glands and the superficial layer of epithelial cell, and that inflammatory cells are expressed more highly in the nasal mucosa of patients with allergic rhinitis compared to those without. In the mucosa of patients with allergic rhinitis, VDR expression level was upregulated compared to that in normal nasal mucosa.

Conclusion: This findings suggest that VDR plays a role in the pathogenesis of allergic rhinitis. Additional research is needed to determine the mechanism and consequences of VDR upregulation.

Keywords: Vitamin D; Vitamin D receptor; VDR; Allergic rhinitis; Nasal mucosa.

\section{INTRODUCTION}

Vitamin $\mathrm{D}$ is an important hormone that has many physiologic roles. It's major role is the regulation of serum level of calcium. In addition, it modulates bone metabolism, blood pressure, and electrolytes. ${ }^{12)}$ Recently, new physiological functions of vitamin $\mathrm{D}$ have been identified. New evidence is that the most active form of vitamin $\mathrm{D}$ which was $25(\mathrm{OH})_{2} \mathrm{D}_{3}$ regulates both innate and adaptive immune systems. ${ }^{3)}$ Vitamin D deficiency is related with susceptibility to infection, especially respiratory infection, also to the occurrence of a various cancers, cardiovascular disease, and autoimmune

\section{Received: May 14, 2021 Revised: July 14, 2021}

Accepted: July 24, 2021

Address for correspondence: Tae Hoon Kim, MD, PhD, Department of Otorhinolaryngology-Head and Neck Surgery, Korea University College of Medicine, Korea University Anam Hospital, 73 Goryedae-ro, Seongbuk-gu, Seoul 02841, Republic of Korea

Tel: +82-2-920-5486, Fax: +82-2-925-5233, E-mail: doctorthk@gmail.com

This is an Open Access article distributed under the terms of the Creative Commons Attribution Non-Commercial License (https://creativecommons.org/licenses/bync/4.0) which permits unrestricted non-commercial use, distribution, and reproduction in any medium, provided the original work is properly cited. diseases. ${ }^{4-7)}$ The occurrence of atopic disease, for example, asthma and anaphylaxis, is also affected by vitamin D. ${ }^{899}$ Furthermore, epidemiological studies showed that serum 25 $(\mathrm{OH})_{2} \mathrm{D}_{3}$ levels are linked to allergic rhinitis, and supplementing vitamin $\mathrm{D}$ in infancy increased the incidence of allergic rhinitis later. ${ }^{10-12)}$

Vitamin D binds to the vitamin D receptors (VDR) and then exerts biological activities, regulating differentiation process of Thelper cell and Th cytokine. ${ }^{13-15)} \mathrm{VDR}$ are steroid thyroid of nuclear receptors which can be found in various cells like airway epithelial and immune cells. ${ }^{16-18)}$ Dysregulation of the VDR contributes to increase prevalence of some autoimmune diseases such as Hashimoto's thyroiditis. ${ }^{19)}$ In animal study, mice deficient in VDR failed to make experimental allergic asthma. ${ }^{20)}$ These results suggest that VDR are related to Th2 cell mediated inflammation and important regulators.

Taken together, it seems that VDR are related to both innate and adaptive immune systems in allergic rhinitis. So, we aimed to identify the VDR expression levels and distribution of VDR in nasal mucosa by comparing normal nasal mucosa 
and the nasal mucosa of patients with allergic rhinitis to assess the possibility of pathogenic role in allergic rhinitis.

\section{MATERIALS AND METHODS}

\section{Tissue samples and preparation}

Total fifty patients were enrolled. Twenty-five patients (13 male and 12 female; range of age, 23-35 years), who had no history of allergy, rhinosinusitis, ongoing medication and smoking, had normal nasal mucosa. They underwent augmentation rhinoplasty, we sampled twenty-five normal mucosa specimen from the inferior turbinate. Other Twentyfive patients (12 male and 13 female; range of age, 21-39 years) had perennial allergic rhinitis, and they underwent septoplasty and turbinectomy surgery. They had typical symptoms of perennial allergic rhinitis, positive multiple allergen simultaneous test to house dust mites or a positive skin prick test and had nasal eosinophilia. And their nasal mucosa of inferior turbinate was edematous and congestive. During septoplasty and turbinate surgery, we sampled allergic rhinitis mucosa specimen from the inferior turbinate.

The informed consent and study protocols were approved by Institutional Review Boards of our institution (2018AN0061), prior to obtaining tissue specimen. Fifteen normal nasal mucosa and 15 allergic rhinitis mucosal samples were split into two parts. After dissecting one part, it was frozen in liquid nitrogen and stored at $-70^{\circ} \mathrm{C}$, followed by RNA isolation. Another part was used for protein isolation. Tissue specimens (10 normal mucosa and 10 allergic rhinitis mucosa) were fixed overnight in a fixative containing $4 \%$ paraformaldehyde in phosphate-buffered saline (PBS) ( $\mathrm{pH} 7.4$ ) for immunohistochemical analysis.

\section{Total RNA isolation, reverse}

transcriptase-polymerase chain reaction

(RT-PCR), and semiquantitative RT-PCR

From each sample, after the total RNA $(1 \mu \mathrm{g})$ was isolated, reverse transcrition was done in $20 \mu \mathrm{L}$ of a reaction mixture which contains $50 \mathrm{pmol}$ of random hexanucleotides and 2.5 $\mathrm{U}$ of Moloney murine leukemia virus reverse transcriptase (RT) (GIBCO BRL, Grand Island, NY, USA) at $42^{\circ} \mathrm{C}$ for 1 hour. The success of the reverse transcription reaction and the integrity of RNA were observed by PCR amplification of glyceraldehyde-3-phosphate dehydrogenase-(GAPDH) transcripts. A negative control was also designed. A difference of negative control is that when cDNA synthesis in each specimen, RT enzyme was omitted.

The primer sequences of the VDR and GAPDH gene which was used in our study were VDR (350 bp), S, 5'-TCGTCCAGCTTCTCCAATCT-3', and AS, 5'-GAACTT-
GATGAGGGGCTCAA-3' and GAPDH (502 bp), s, 5'-ATCTTCCAGGAGCGAGATCC-3', and AS, 5'-ACCACTGACACGTTGGCAGT-3'.

We performed semiquantitative RT-PCR to evaluate the differential expression of each gene mRNA in the normal mucosa and allergic rhinitis mucosa. To quantify the PCR products of all samples, densitometry was used to analyze the predicted bands. The relative intensity of each gene was defined as divided by GAPDH cDNA. The standard deviation of a data is 6. Mann-Whitney $U$ test was used for statistical significance of the differences, and the significance level was set at $\mathrm{p}<0.05$.

\section{Immunohistochemical staining and western blot analysis}

With a peroxidase-labeled streptavidin-biotin technique, Immunohistochemical staining was executed. To sum up, in 1:250 dilution of anti-VDR monoclonal antibody (Pierce Biotechnology, USA) under condition of $4^{\circ} \mathrm{C}$, paraffin sections $(4 \mu \mathrm{m})$ were incubated overnight. For a negative control, IgG from rat without an immune system was used as a replacement for the primary antibodies. For representing the color, 3,3'-diaminobenzidine was used. For Western blot analysis, in a buffer solution which contains $150 \mathrm{mM} \mathrm{NaCl}$, $50 \mathrm{mM}$ Tris- $\mathrm{HCl}$ ( $\mathrm{pH} 8.0$ ), and a proteinase inhibitor cocktail, Frozen tissues were shattered and mixed up strongly. The protein $(50 \mu \mathrm{g})$ extracted from this process was boiled for five minutes in a sodium dodecyl sulfate sample buffer. Through the $12 \%$ sodium dodecyl sulfate polyacrylamide gels, the same amounts of total protein were separated and transferred to immobilon (Millipore, Bedford, MA, USA). Overnight under room temperature conditions, in PBS with Tween 20 (Polysorbate 20), the blots were incubated with anti-VDR monoclonal antibody. Through the enhanced chemiluminescence detection kit (Amersham Biosciences, Piscataway, NJ, USA), Antibody reaction was found. And the chemiluminescence was found on x-ray film. For an internal control, the anti- $\beta$-actin antibody (Santa Cruz Biotechnology, Inc., CA, USA) was used to analyze the $\beta$ - actin expression in parallel blots. Scion Image Beta 4.0.2 (Scion Corp., Frederick, MD, USA) was used to quantify the intensity of detected bands. The relative intensity of each protein signal was defined as divided by $\beta$-actin signals. Mann-Whitney $U$ test was used for statistical significance of the differences, and the significance level was set at $\mathrm{p}<0.05$. 


\section{RESULTS}

The expression of VDR mRNA expression in normal human nasal mucosa and allergic nasal mucosa by RT-PCR

VDR and GAPDH mRNA expressions were identified in total RNA isolation which was from normal nasal mucosa and allergic rhinitis mucosa by RT-PCR. It shows that both normal nasal mucosa and allergic rhinitis mucosa had VDR mRNAs expression (Fig. 1A). VDR PCR products were correspond to $350 \mathrm{bp}$. And GAPDH mRNA PCR products were corresponded to $502 \mathrm{bp}$. PCR products sequence was same with the published sequence. No bands appeared in the negative control reaction without reverse transcription in the cDNA synthesis process, that means genomic DNA in the RNA samples were not contaminated (data not shown). The relative intensity of VDR to GAPDH was significantly higher in allergic rhinitis mucosa compared to normal nasal mucosa (Fig. 1B) $(\mathrm{p}<0.05)$.

\section{Immunohistochemical localizations and western blotting of VDR in normal nasal mucosa and allergic nasal mucosa}

Immunohistochemical staining of all normal nasal mucosa and allergic rhinitis mucosa samples showed a same pattern (Fig. 2). In normal mucosa, VDR were located in the submu-
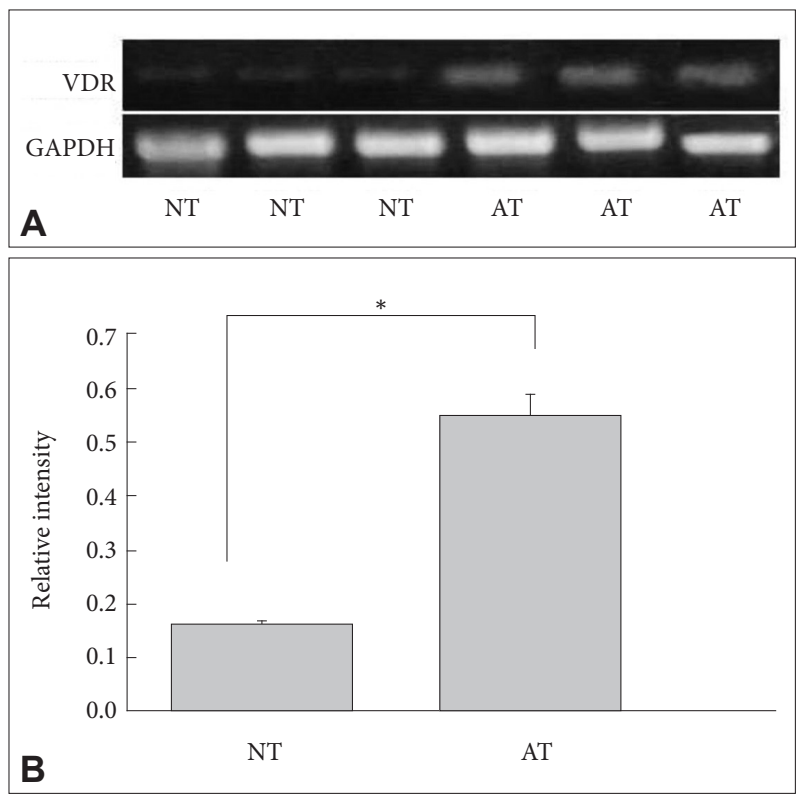

Fig. 1. A: Semiquantitative reverse transcriptase-polymerase chain reaction analysis of VDR mRNA level in normal and allergic nasal mucosa. B: Bands were quantified by densitometric scanning and the relative amount of each gene was calculated by dividing by the internal control, GAPDH. The bar indicates the mean \pm SD. ${ }^{*} p<0.05$. NT, normal inferior turbinate mucosa; AT, allergic inferior turbinate mucosa; VDR, vitamin D receptors. cosal gland and epithelial cell. The intensity of staining was weak in the submucosal glands and epithelial cell (Fig. 2A). However, in allergic nasal mucosa, the intensity of VDR staining were higher in the submucosal glands and epithelial cell (Fig. 2B), which showed nuclear location (Fig. 2C and D). Furthermore, inflammatory cells, which was infiltrated in the nasal mucosa, showed VDR immunoreactivity (Fig. 2B). In western blot analysis, both VDR and $\beta$-actin were identified in normal nasal mucosa and allergic rhinitis mucosa (Fig. 3A). The relative intensity of VDR to $\beta$-actin was significantly higher in allergic rhinitis mucosa compared to normal nasal mucosa (Fig. 3B) $(\mathrm{p}<0.05)$. It means that VDR expression levels were higher in allergic rhinitis mucosa compared to normal mucosa.

\section{DISCUSSION}

To obtain a new perspective on the VDR of the normal mucosa and the allergic mucosa, we studied the expression and the distribution of VDR in normal and allergic nasal mucosa. In the present study VDR expression was found in both the normal and allergic nasal mucosa. Immunohistochemical staining showed the VDR expression in the epithelium and submucosal glands of normal nasal mucosa and allergic nasal mucosa as well. Further, VDR was located in the inflammatory cells in the nasal mucosa, which was strongly expressed in the allergic nasal mucosa. Western blotting verified these immunohistochemical results, which demonstrated that the levels of expression of VDR protein in allergic nasal mucosa were increased compared to normal nasal mucosa. Taken together, the present study imply that VDR is constitutively expressed in normal nasal mucosa and increased in allergic nasal mucosa, suggesting VDR may play a role in the pathophysiology of normal and allergic nasal mucosa. This is the first analysis of the expression and distribution of VDR mRNA and protein in the human nasal mucosa.

At mRNA and protein levels, VDR were expressed in the normal and allergic nasal mucosa. Additionally, our study confirmed that nuclear locations of VDR were found in the superficial layer of the epithelium and submucosal glands. Menezes et al. ${ }^{21)}$ reported that most healthy bronchial tissue showed moderate nuclear immunoreactivity for VDR was in epithelial cells. In healthy skin, immunoreactivity for VDR was consistently confined to nuclei in keratinocytes of all epidermal layers. ${ }^{22)}$ These findings are consistent with our study results. In human nasal mucosa, the epithelial cells of nasal mucosa and submucosal gland play an important role in the immune system by participating in immune regulations. They express the surface antigens, secrete various macromolecules, and synthesize cytokines. ${ }^{2324)}$ Consequently, the location of 


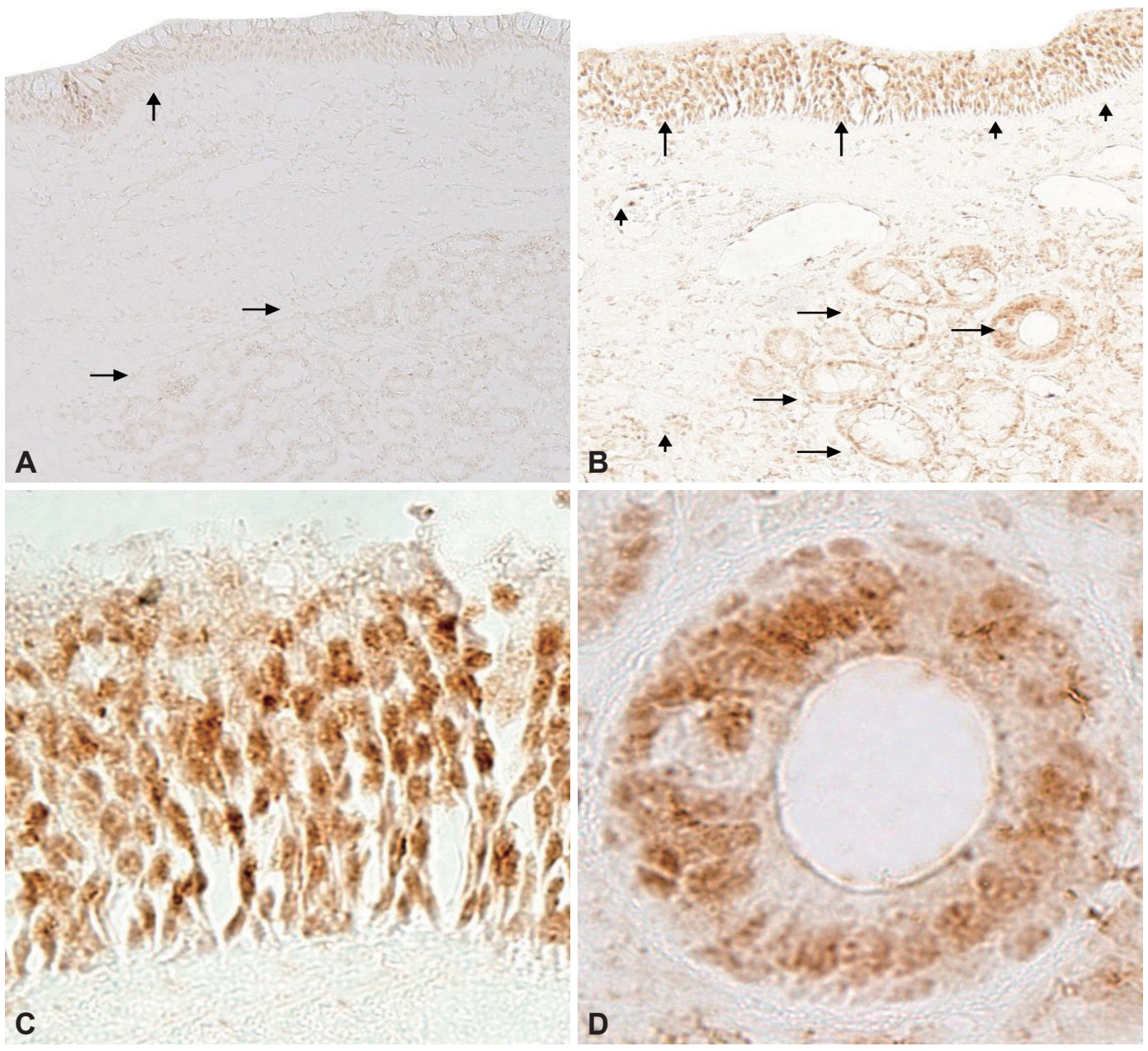

Fig. 2. Immunohistochemical localization of VDR in normal nasal mucosa (A) and allergic nasal mucosa (B, C, D). Expression of VDR was largely weak in epithelial cells (vertical arrows) and submucosal glands (horizontal arrows) in normal nasal mucosa (A) whereas VDR was intensely expressed in the superficial epithelium (vertical arrows) and submucosal glands (horizontal arrows) in allergic nasal mucosa (B), which showed nuclear location (C, D). In addition, inflammatory cells (arrow heads) infiltrating into the nasal mucosa also showed VDR immunoreactivity (B). Vertical, horizontal arrow indicates epithelial cells, submucosal glands respectively and arrowhead shows inflammatory cells ( $A$ and $B$, original magnification, $\times 100 ; C$ and $D$, original magnification, $\times 400)$. VDR, vitamin $D$ receptors.

the VDR appears to be ideal for effective immune system regulators in the nasal mucosa. However, further researches are necessary for finding out the potential role of VDR in the normal nasal mucosa.

Immunohistochemical staining results showed that VDR were also located in the inflammatory cells, which were more expressed in the allergic rhinitis mucosa intensely. VDR protein expression levels in allergic nasal mucosa were much higher than normal nasal mucosa. Many studies have been conducted on the association between VDR and various diseases. VDR deficient mice showed increased sensitivity to immune diseases such as inflammatory bowel disease, rheumatoid arthritis, and increased thrombogenicity, risk of cancer. ${ }^{25-27)}$ Wittke et al. ${ }^{20)}$ reported that mice deficient in VDR did not develop experimental allergic asthma. In addition, in VDR deficient lung cells, infiltrated eosinophils, pathogenic lym- phocytes were decreased and the development of airway hyperresponsiveness has been reduced. ${ }^{20)}$ Combining these results, it can be suggested that VDR are significantly important in the pathogenesis of various diseases, including immune diseases and will play an important role in allergic rhinitis.

There have been many studies about the relationship between vitamin D and allergic rhinitis. In immunologic aspect, vitamin $\mathrm{D}$ inhibit $\mathrm{T}$ cell and transcription of Th17, so that lead to switch from Th1 to Th2, causing allergic rhinitis. ${ }^{28)}$ Wjst and Hypponen ${ }^{11)}$ reported that the patients with allergic rhinitis have increased vitamin D serum level compared with normal control. In other recent studies, deficiency of vitamin D was more usual in the patients with allergic rhinitis. ${ }^{10}$ And serum vitamin D levels in allergic rhinitis were lower than non-allergic rhinitis patients. ${ }^{29)}$ However, it's receptor, VDR expression in the allergic rhinitis nasal mucosa has never 


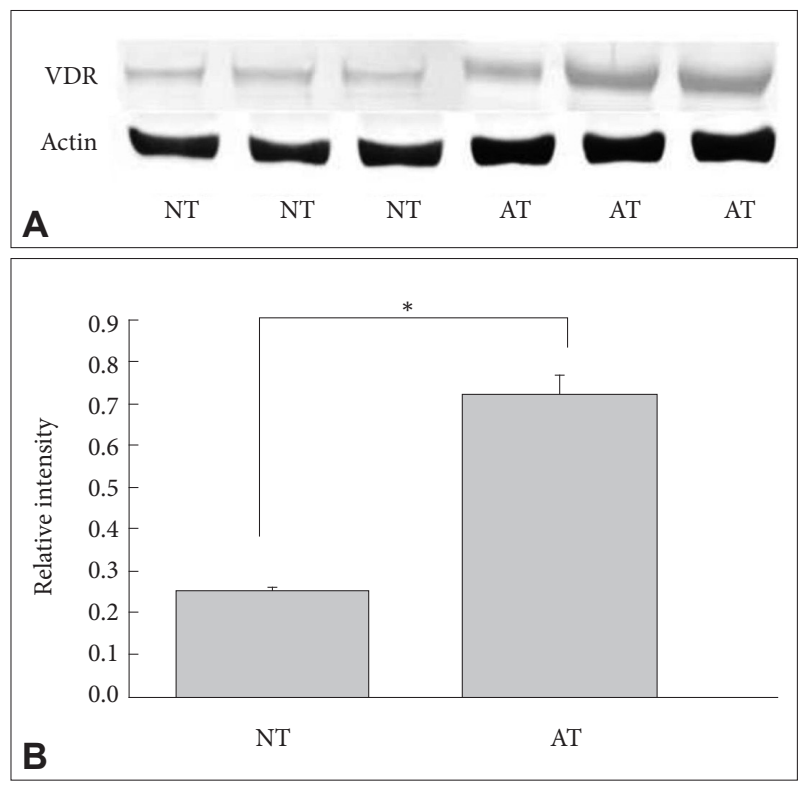

Fig. 3. A: Western blot analysis of VDR in normal and allergic nasal mucosa. B: Bands were quantified by densitometric scanning and the relative amount of each gene was calculated by dividing by the internal control, actin. The bar indicates the mean \pm SD. ${ }^{*} p<0.05$. NT, normal inferior turbinate mucosa; AT, allergic inferior turbinate mucosa; VDR, vitamin D receptors.

been investigated. The present study is the first experiment in order to study VDR expression and distributional patterns of VDR mRNA and protein in the normal and allergic nasal mucosa.

Limitations of the present study are that we only took a snap shot of VDR in human nasal mucosa and didn't elucidate the mechanism how VDR have been increased in allergic nasal mucosa and the results of VDR upregulation. Therefore, further studies will be needed to find out why VDR were upregulated and what is the results of VDR upregulation in allergic rhinitis to clarify the roles of VDR in allergic nasal mucosa.

\section{Conclusion}

This study identified that VDR were expressed in the normal mucosa and allergic nasal mucosa, and the VDR were located in the submucosal gland and epithelial cells, as well as inflammatory cells which were more expressed in allergic nasal mucosa. The VDR expression levels were upregulated in allergic nasal mucosa compared to normal mucosa. Our study results can contribute to suggest new therapeutic target in the pathogenesis of allergic rhinitis. But, additional researches are necessary for finding out mechanism of VDR upregulation.

\section{Conflicts of Interest \\ The authors have no potential conflicts of interest to disclose.}

\section{Author Contributions}

Conceptualization: Tae Hoon Kim. Data curation: Hyeon Geun Kim. Formal analysis: Tae Hoon Kim. Funding acquisition: Tae Hoon Kim. Investigation: Hyeon Geun Kim. Methodology: Tae Hoon Kim. Project administration: Tae Hoon Kim. Resources: Hyeon Geun Kim. Software: Hyeon Geun Kim. Supervision: Da Bin Lee, Tae Hoon Lee, Bo Yoon Choi, Mun Soo Han, Sang Hag Lee. Validation: Hyeon Geun Kim. Visualization: Hyeon Geun Kim. Writing-original draft: Hyeon Geun Kim. Writing-review \& editing: Hyeon Geun Kim, Tae Hoon Kim.

\section{ORCID iDs}

Hyeon Geun Kim https://orcid.org/0000-0002-0174-279X

Da Bin Lee https://orcid.org/0000-0003-4457-6450

Tae Hoon Lee https://orcid.org/0000-0002-7362-6798

Bo Yoon Choi https://orcid.org/0000-0002-8511-7966

Mun Soo Han https://orcid.org/0000-0003-1359-6248

Tae Hoon Kim https://orcid.org/0000-0001-8811-654X

Funding Statement

None

\section{REFERENCES}

1) Demay MB. Mechanism of vitamin D receptor action. Ann N Y Acad Aci 2006;1068(1):204-13.

2) Sassi F, Tamone C, D'Amelio P. Vitamin D: nutrient, hormone, and immunomodulator. Nutrients 2018;10(11):1656.

3) Aranow C. Vitamin D and the immune system. J Investig Med 2011; 59(6):881-6

4) Liu PT, Stenger S, Tang DH, Modlin RL. Cutting edge: vitamin D-mediated human antimicrobial activity against Mycobacterium tuberculosis is dependent on the induction of cathelicidin. J Immunol 2007; 179(4):2060-3.

5) Garland CF, Garland FC, Gorham ED, Lipkin M, Newmark H, Mohr $\mathrm{SB}$, et al. The role of vitamin $\mathrm{D}$ in cancer prevention. Am J Public Health 2006;96(2):252-61.

6) Cantorna MT. Vitamin D and its role in immunology: multiple sclerosis, and inflammatory bowel disease. Prog Biophys Mol Biol 2006; 92(1):60-4.

7) Marquina C, Mousa A, Scragg R, de Courten B. Vitamin D and cardiometabolic disorders: a review of current evidence, genetic determinants and pathomechanisms. Obes Rev 2019;20(2):262-77.

8) Camargo CA Jr, Rifas-Shiman SL, Litonjua AA, Rich-Edwards JW, Weiss ST, Gold DR, et al. Maternal intake of vitamin D during pregnancy and risk of recurrent wheeze in children at $3 \mathrm{y}$ of age. Am J Clin Nutr 2007;85(3):788-95.

9) Devereux G, Litonjua AA, Turner SW, Craig LC, McNeill G, Martindale $\mathrm{S}$, et al. Maternal vitamin $\mathrm{D}$ intake during pregnancy and early childhood wheezing. Am J Clin Nutr 2007;85(3):853-9.

10) Arshi S, Ghalehbaghi B, Kamrava SK, Aminlou M. Vitamin D serum levels in allergic rhinitis: any difference from normal population? Asia Pac Allergy 2012;2(1):45-8.

11) Wjst M, Hypponen E. Vitamin D serum levels and allergic rhinitis. Allergy 2007;62(9):1085-6.

12) Hypponen E, Sovio U, Wjst M, Patel S, Pekkanen J, Hartikainen AL, et al. Infant vitamin D supplementation and allergic condition in adulthood. Nothern Finland birth cohort study 1966. Ann N Y Acad Sci 2004;1037(1):84-95.

13) Boonstra A, Barrat FJ, Crain C, Heath VL, Savelkoul HF, O'Garra A. 1a,25-dihydroxyvitamin $\mathrm{D} 3$ has a direct effect on naive $\mathrm{CD} 4+\mathrm{T}$ cells to enhance the development of Th2 cells. J Immunol 2001;167(9): 4974-80.

14) Mahon BD, Wittke A, Weaver V, Cantorna MT. The targets of vitamin 
$\mathrm{D}$ depend on the differentiation and activation status of $\mathrm{CD} 4$ positive T cells. J Cell Biochem 2003;89(5):922-32.

15) Overbergh L, Decallonne B, Waer M, Rutgeerts O, Valckx D, Casteels $\mathrm{KM}$, et al. 1alpha,25-dihydroxyvitamin D3 induces an autoantigenspecific T-helper 1/T-helper 2 immune shift in NOD mice immunized with GAD65 (p524-543). Diabetes 2000;49(8):1301-7.

16) Nagpal $S$, Na S, Rathnachalam R. Noncalcemic actions of vitamin $D$ receptors ligands. Endocr Rev 2005;26(5):662-87.

17) Nguyen TM, Guillozo H, Marin L, Tordet C, Koite S, Garabedian M. Evidence for a vitamin D paracrine system regulating maturation of developing rat lung epithelium. AM J Physiol 1996;271(3 Pt 1):L392-9.

18) Wang Y, Zhu J, DeLuca HF. Where is the vitamin D receptor? Arch Biochem Biophys 2012;523(1):123-33.

19) Proal AD, Albert PJ, Marshall TG. Dysregulation of the vitamin D nuclear receptor may contribute to the higher prevalence of some autoimmune diseases in women. Ann N Y Acad Sci 2009;1173(1): 252-9.

20) Wittke A, Weaver V, Mahon BD, August A, Cantorna MT. Vitamin $D$ receptor-deficient mice fail to develop experimental allergic asthma. J Immunol 2004;173(5):3432-6.

21) Menezes RJ, Cheney RT, Husain A, Tretiakova M, Loewen G, Johnson CS, et al. Vitamin D receptor expression in normal, premalignant, and malignant human lung tissue. Cancer Epidemiol Biomarkers Prev 2008;17(5):1104-10.
22) Milde P, Hauser U, Simon T, Mall G, Ernst V, Haussler MR, et al. Expression of 1,25-dihydroxyvitamin D3 receptors in normal and psoriatic skin. J Invest Dermatol 1991;97(2):230-9.

23) Porzia A, Cavaliere C, Begvarfaj E, Masieri S, Mainiero F. Human nasal immune system: a special site for immune response establishment. J Biol Regul Homeost Agents 2018;32(1 Suppl 1):3-8.

24) Lane AP. The role of innate immunity in the pathogenesis of chronic rhinosinusitis. Curr Allergy Asthma Rep 2009;9(3):205-12.

25) Bouillon R, Carmeliet G, Verlinden L, van Etten, E, Verstuyf A, Luderer HF, et al. Vitamin D and human health: lessons from vitamin D receptor null mice. Endocr Rev 2008;29(6):726-76.

26) Punceviciene E, Gaizevska J, Sabaliauskaite R, Venceviciene L, Puriene A, Vitkus D, et al. Vitamin D and VDR gene polymorphisms' association with rheumatoid arthritis in lithuanian population. Medicina (Kaunas). 2021;57(4):346.

27) Du C, Yang S, Zhao X, Dong H. Pathogenic roles of alterations in vitamin $\mathrm{D}$ and vitamin $\mathrm{D}$ receptor in gastric tumorigenesis. Oncotarget 2017;8(17):29474-86.

28) Tian HQ, Cheng L. The role of vitamin D in allergic rhinitis. Asia Pac Allergy 2017;7(2):65-73.

29) Restimulia L, Pawarti DR, Ekorini HM. The relationship between serum vitamin D levels with allergic rhinitis incidence and total nasal symptom score in allergic rhinitis patients. Open Access Maced J Med Sci 2018;6(8):1405-9. 